\title{
Narratives of transition from social to enterprise: You can't get there from here!
}

\section{Introduction}

Ten or so years ago it would have seemed like an oxymoron to amalgamate the terms social and enterprise. Since that time the concept has rapidly passed from obscurity to the status of orthodoxy (Arthur et al. 2009, p.208)

Social enterprise has become an umbrella term for forms of organisation that trade for social purposes (Peattie and Morley, 2008; Ridley-Duff and Bull, 2011). Arthur et al.'s (2009) views of the fusing of social and enterprise offers the beginnings for the rationale for exploring narrative in this article. Across North America, Australia, Europe and the United Kingdom, social enterprise is portrayed as the business model for solving societal problems (Nicholls, 2006; Westall and Chalkley, 2007; Chell et al., 2010). In England, which is the focus of this article, policy has increasingly elided social enterprise and social entrepreneurship with social organisations that compete for contracts to deliver welfare provision (Nicholls, 2010; Teasdale, 2011). In what follows we are concerned with the transition of existing social organisations responding to imperatives from central government to generate income through competition for the delivery of public services.

By social organisations we mean those in the third sector or civil society, terms heavily invested with political dimensions and sectoral interests (Alcock, 2010). They are extremely diverse, and include charities, voluntary organisations, community groups, credit unions, and faith based organisations. Such organisations have been described as moving towards social enterprise with the image of a tide, a force that is irresistible yet positive. Dees (1998, p. 56), for example, dubbed the transition as the 'rising tide of commercialisation' in the social economy and Boschee (2006, p. 359) described a tide that is the 'changing face of England's voluntary and community sector'. This is a perspective that tends to dominate social enterprise policy and programmes, as well as much academic writing, as discussed below, but there is also scepticism towards its imagery and 
storylines (Curtis, 2008; Parkinson and Howorth, 2008; Scott, 2010). An expanding body of critique emphasises threats to the distinctiveness of social organisations when they move from social to economic goals (Eikenberry and Kluver, 2004; Haugh and Kitson, 2007; Bull, 2008).

In order to navigate the claims of enthusiasm and the counter claims of scepticism we draw upon the insight of Dey and Steyaert (2010) that the social enterprise narrative can be categorised as: the grand narrative, the counter narrative and little narratives. The 'grand' is the dominant narrative invoking rationalism, utility, progress and individualism in 'an optimistic script of social change' (ibid, p.86). Within this narrative are strong normative assumptions that by becoming more entrepreneurial, enterprises become efficient and reliable in ways that fit the modernisation agenda for public services, including co-production between the public and third sectors (Baines et al., 2010; Pestoff and Brandsen, 2010). The 'counter' narrative opposes this harmonious story of meeting social and economic goals, and alludes to history and context to question 'the novelty and “taken-for-grantedness” of the grand narrative' (Dey and Steyaert, 2010, p. 93). 'Little' narratives, like the counter-narratives, offer alternative interpretations; but instead of offering either/or stories to 'go beyond the present narrative representation ... trying to think what is currently unthinkable inside of or in the centre of the grand narrative' (ibid., p.87). This approach is consistent with the need to consider multiple interpretations, which has become increasingly recognised in entrepreneurship literature (Cope, 2005; Steyaert and Hjorth, 2005).

We write in the spirit of critical plurality and are influenced by the theoretical approach to narratives of enterprise and entrepreneurship (Down, 2006; Down and Warren, 2008; Jones et al., 2008). Our overall aim is to advance understanding of the contested transitions of social organisations that are working in collaboration with public sector agencies and responding to imperatives from central government to generate income through competition for the delivery of public services. To this end we report on interpretivist research undertaken in the North of England with practitioners in social organisations and support agencies. The research utilised interviews alongside drawings created by research participants to explore where they identify and locate their organisations. Our specific objectives are threefold. Firstly, we address a lacuna in the 
literature regarding contemporary social enterprise from the experience and understanding of practitioners (Chell, 2007; Hjorth, 2007; Dey and Steyaert, 2010). Secondly, we draw upon interactions with practitioners to offer new reflections upon widely used images that represent social enterprise along a dichotomous, polar spectrum from social to economic. Our third objective is methodological. We seek to introduce to the repertoire of social enterprise research the novel and inventive use of visual methods.

The article is structured in the following sections: a review of the literature focusing on the competing narratives; the study design, its conceptual underpinning, and rational for the combination of visual and narrative methods employed; interpretations of the findings as narratives; implications for theory and practice; and concluding thoughts.

\section{Narrative of transition: literature review}

There has been much attention to attempting to clarify what is and is not a social enterprise (Defourny and Nyssens, 2006; Nicholls, 2006; Bacq and Janssen, 2011). We employ the terms social enterprise and social entrepreneurship, recognising that both are in widespread usage and that the nuances of each are much debated (Birch and Whittam, 2008). In this review section we avoid any attempt at a single definition of social enterprise. On the contrary, we recognise and highlight contradictions that accurately reflect struggles over the concept (Ridley-Duff and Bull, 2011). Our focus is on how significant differences are framed in social enterprise through emphases on the social and the economic. We begin by discussing how social enterprise is represented in the form of a continuum and go on to consider narratives with particular emphasis on movement across this continuum.

Narratives are deployed to order and give meaning to experience (Czarniawska, 1998; Brown et al., 2005; Hjorth, 2007). Governments, organisations, professional groups and individuals all construct preferred narratives in which events are selected and arranged for particular audiences (Riessman, 1993). Froggett and Chamberlayne (2004, p.71) underline a wider context of a political culture that values an 'entrepreneurial action story' and find the language 'emphasises individualism, consumerism, social enterprise and knowledgebased modernization in defining processes of personal and community change'. The nature 
of narrative, according to Dunford and Jones (2000, p. 1209), is 'to persuade others towards certain understandings and actions'. Weick (1995) and Gartner (2007) argue that narratives are more than just words; they affect how you act.

\subsection{Framing social enterprise between the economic and the social}

Within the theoretical development of social enterprise, influential linear models are used to frame the concept of social enterprise based on the social and economic. These primarily depict the social and economic positioned at opposite ends of a spectrum (Dees, 1998; Alter, 2004; Dees and Anderson, 2006). An example is Figure 1 (adapted from Dees, 1998). At one end of the continuum are 'purely philanthropic' goals and at the other 'purely commercial' goals. We dwell upon this image and reproduce it because it has, according to Peattie and Morley (2008), influenced the entire social enterprise research agenda. The linear construct serves to frame two opposing perspectives: one emphasises the economic, where actions are purely commercial (Dees, 1998; Boschee, 2006; Perrini, 2006); the other, in contrast, highlights the social component, where actions are purely philanthropic (Grenier, 2002; Foster and Bradach, 2005; Howorth et al., 2011). Whilst tensions between the social and economic are commonly recognised, there remains a theme of balancing, similar to notions of equilibrium, the 'hybrid nature' of mission and market objectives (Alter, 2004).

[Figure 1 here]

As discussed below, the imagery of the social enterprise continuum is invoked in talk of transitions from one pole to the other. This is reflected in policy and academic accounts that urge organisations to move from one state (social organisation) towards another perceived as more desirable (social enterprise). With the linear spectrum still in mind, we turn now to narratives of social enterprise.

\subsection{The grand narrative: Theoretical point of departure}


The grand narrative is synonymous with the dominant discourse and the macro story, and conveys economic growth and development, emphasising heroic individuals, rationality and hierarchy (Berglund and Wigren, 2012). It is articulated by support agencies promoting business models, tools and approaches using a business language construct (Grenier, 2006; Nicholls, 2006). Movement across the spectrum from left to right is both observed and advocated. According to Perrini (2006, p.60) the economic end of the spectrum 'emphasizes entrepreneurship as a way to make non-profits more market-driven, clientdriven, and self-sufficient'. Tracey et al. (2005, p.335) observe that social enterprises are 'encouraged to think and act like businesses ... for example, [using] the language of markets and customers'. They are urged to 'develop requisite entrepreneurial skills to guide the transition from grant-funding to trading' (Mason et al., 2007, p.286). Entrepreneurship in this vein is a familiar trope in the grand narrative.

Largely based upon the crisis in the welfare systems, Defourny and Nyssens (2006) find a new entrepreneurship is more prevalent in Europe than the US and is most striking in the UK due to changes in public sector services. The rise to prominence of social enterprise is closely entangled with a crisis in welfare systems and reduced state engagement in the direct delivery of public services (Defourny and Nyssens, 2006; Nicholls, 2010; Hogg and Baines, 2011). This view is ubiquitous in government documents offering a positive story of the process of social enterprise for solving numerous societal problems (DTI 2002; HM Treasury, 2002; OTS, 2007) and in strands of academic literature (Dees and Anderson 2006; Nicholls, 2006; Nyssens, 2006). The language of entrepreneurship is significant in the grand narrative because it is associated with imperatives for the transformation of social organisations from the third sector facing new demands and opportunities in the context of the public sector.

Thorough discussion of entrepreneurship theory and debates is beyond the scope of this article. We briefly highlight some key entrepreneurial themes that resonate strongly - and controversially - within narratives of social enterprise. Classically, entrepreneurs are said to pursue opportunity and effect change (Shane and Venkataraman, 2000). Proactivity, risk-taking and innovation characterise entrepreneurship as an individual and/or organisational phenomenon (Casson, 2005). There has been a shift from seeing entrepreneurship through individual attitudes and behaviour towards more emphasis on the processes of discovering and co-producing opportunities, and the various contexts in which that happens (Steyaert, 2007; Down, 2010). 
Although the desirable connotations of entrepreneurship are largely taken for granted, there are dissenting voices (du Gay, 2004). According to the philosophical reflections of Jones and Spicer (2009, p.37) entrepreneurship is 'indefinable, vacuous and empty'. Academic study, it has been argued from within the discipline, has 'suffered from an often unquestioned positive ideological stance towards entrepreneurship and small business' (Blackburn and Kovalain, 2009, p.129). Echoing Hans Christian Andersen's story of The Emperor's New Clothes, Berglund and Wigren (2012, p.11) highlight; 'those not viewing themselves entrepreneurially may have difficulty in dressing in the clothes of the entrepreneur'. This has implications for identity as the people who run social enterprises are often referred to as social entrepreneurs even though they might not refer to themselves as such (Grenier, 2006; Howorth et al., 2011).

\subsection{The counter-and little narrative of social enterprise}

Both the counter and little narratives offer an alternative narrative thread, questioning social enterprise as increasingly dominated by business thinking and movement towards the economic pole. The counter narrative, as employed by Berglund and Wigren (2012), opposes the grand narrative and states the importance of community, non-economic values and how societal structures must be changed. For instance, Eikenberry and Kluver (2004) argue that in the United States the marketization of non-profits, when they increased their share of service provision on behalf of government, has ultimately compromised their democratic contributions. Similar arguments have emerged from academic studies focussing upon the third sector in the UK from disciplines including social policy (Buckingham, 2009), geography (Milligan and Fyfe, 2004) and community studies (Milbourne, 2009).

These issues link to a wider agenda. Whilst Grenier (2002) claims social enterprise is understood within political and economic frameworks, rather than challenging them, it appears assumed by those developing the counter-narrative that the grand narrative is a negative influence being forced upon transforming third sector organisations by more powerful agencies. Thus, the counter narrative critiquing social enterprise appears to have become entangled with idealised or moral arguments of polarized positions between the social and the economic with radical actions to oppose the powerful mainstream stance 
(Dey and Steyaert, forthcoming). For critics, a worrying feature of the grand and counter narratives is that values and meanings behind the social have become 'extremely poor and simplified' (Dey and Steyaert, 2010, p.97).

In the empirical section of this article, we develop little narratives as a way of supporting more nuanced analysis of the field. Rather than depicting the actions of social enterprise as polar opposites, a notion is required to negotiate meanings between the grand (dominant) narrative emphasising harmonious economic and social aims and the radical or deviant story of the counter-narrative. It is useful at this point to think about how paradox can be invoked in social enterprise (Curtis, 2008; Scott, 2010). This issue is wider than the paradox as seen as the contradiction between social and economic goals of social enterprise. Goldstein et al. (2008) argue that social enterprise situations are complex and unpredictable. As they state one issue is information, the 'difference that makes a difference', especially as there are differences in perspectives and interpretations of social enterprise. Related to this point, we draw upon theorizing outside of the social enterprise literature. For instance, Rodgers (2007) challenges the idea of focussing upon rational decision-making processes, claiming there is value to be found in embracing paradox and questioning unspoken assumptions. The value of paradox is 'in stimulating people to think outside conventional frames and thereby induce change' (Darwin et al., 2002, p.197). It is here that little narratives come to the fore. Little narratives are utilised in the entrepreneurship literature to offer insights to identities, current situations and possible futures (Hjorth, 2007). Little narratives offer a means for practitioners and theorists to accommodate the 'paradoxes, contradictions and complexities of daily practice' (Dey and Steyaert, 2010, p.98). Moreover, Steyaert and Hjorth (2005) and Dey and Steyaert (2010) claim the little narratives have less presence in the literature, yet without them there are limits to alternative ways of thinking and talking.

This section has offered a brief overview of relevant literature and illustrated the representations of social and economic within the social enterprise spectrum and differing narratives of social enterprise. It has highlighted the grand, counter and little narratives and the associated economic and business language and context. These contested views highlight the on-going debates of meaning between academics, practitioners and policymakers. Paradox is suggested as a crucial aspect of the little narratives. Methodology and data collection - narratives of social organisations and support agencies 


\section{Methodology and data collection - narratives of social organisations and support agencies}

Date were generated by two independent qualitative studies, both of which sought to capture the views and experiences of decision makers in social organisations and advisors in sector support agencies promoting social enterprise. The research was underpinned by interpretative social science traditions, which broadly prioritise meanings and sensemaking, rather than counting and classifying phenomena. Both studies utilised a narrative approach to the stories that people tell, exploring what they say about what they do (Gartner, 2007). Both combined narratives recounted in interviews with another set of techniques in the form of visual stimulations presented to interviewees and drawings elicited from them.

Whilst visual research is a quickly growing field with a variety of approaches to interpretive processes (Mitchell, 2011), the use of participants' drawings is not well established in enterprise research. However, Meyer (1991) urges researchers to exploit the power of drawings, and Stiles $(2004, \mathrm{p} .127)$ argues that 'images can be as valuable as words or numbers in exploring organizational constructs'. Images made by research participants are increasingly used in the fields of education, health and community development along with interviews (Prosser and Loxley, 2008), and they can be particularly fruitful when 'the drawing flows smoothly as a continuation of the narrative' (Guillemin, 2004, p.277). We followed Rose's (2008) guidelines which suggest that jointefforts in visual materials should include images selected by researchers, as a prompt for reflection and sense making with the research participants. We facilitated research participants to 'move from description to depiction to theorising the reasons for the ways in which they represented features ... through drawing and talking' (Emmel, 2008, p.2).

Both studies took place in the north of England between 2004 and 2007. One was part of a European Social Fund project in Greater Manchester that sought to support the development of social enterprise in the region and the other a private consultancy project conducted for a successful Local Enterprise Growth Initiative bid in Bradford, and later part of a PhD. Thus, the research in both cases had practical and theoretical aims. The two studies shared a primary focus of impacts of change associated with social enterprise experienced in contemporary practice. 
We sought multiple stories of social enterprise. In total fifty-eight people were interviewed across the two studies (thirty-six from social organisations and twenty-two advisors). A purposive sampling strategy was undertaken and the research participants chosen were seen as 'informed experts' (Liamputtong and Ezzy, 2005). Participants were all paid staff, employed either in existing organisations and agencies responsible for decision-making and managing social enterprise or third sector projects and programmes in their organisations, or support services which were perceived as social enterprise activity (either funded or described as such). Both studies interviewed advisors from sector support agencies offering business advice to social enterprise. We include interview material from advisors, as their embeddedness within the transitions of the organisations within our study is a key influence in the changing environment. As Berglund and Wirgen (2012, p.13) note, policy makers are becoming 'entrepreneurship writers' in setting up programmes and projects.

By undertaking a narrative approach, where interactions and different views are sought, insights into contemporary practices and negotiations in relationships between those engaged in social enterprise support and those in social organisations delivering public services are also offered. The researchers interviewed people from social organisations engaged in the delivery of services such as social care, arts, health, safeguarding the environment and increasing participation in sport. At the time there were initiatives from central government intended to increase public service delivery by social organisations, to promote their readiness to compete for contracts and to reduce their dependency on grant income. All the research participants were responding to this context. All study organisations had a minimum of three paid workers but fewer than fifty, and were formally constituted, with legal forms including Companies Limited by Guarantee and Industrial and Provident Societies. Some - but not all - identified their organisations as 'social enterprises', although all were characterised as such by others, particularly support advisors.

The research data consisted of participants' stories and drawings. As such, the focus was on listening to and seeing how the re-telling of micro-stories of everyday practice and redrawing academic models differs from, or echoes, the grand macro narrative as well as 
the counter narratives. The early parts of the interviews were exploratory and during the later stages visual images of the social enterprise continuum were introduced to supplement and enrich interview discussions. Participants were shown a simplified social enterprise spectrum (Dees, 1998; Dees and Anderson, 2006). They were given pencils and asked to draw upon the model and to describe experiences. Emergent data, similar to Warren (2009), was elicited where meaning was actively created in interactions between researcher and participant, requiring co-operation between both over the production and understanding of meanings and contexts of the images. We sought to explore if and how research participants would interact with the models to make sense of social enterprise. This added an element of uncertainty, as responses were at times unexpected and surprising to the researchers. Some chose to draw carefully on the spectrum and others demonstrated their views with forceful pencil movements. Thus, the process by which the images were created highlighted the emotional and non-rational nature of understanding social enterprise.

In identifying how differing narratives were negotiated, transcripts were read and re-read and drawings compared. The researchers initially wrote notes independently to trace the development of ideas. Each developed codes manually to address 'questions about how social experience is created and given meaning' (Eisenhardt and Graebner, 2007, p.28). Only after this were the two sets of data brought together and further developed and changed to better reflect the key stories and drawings that influenced participants. During analysis, the notion of codes became less important and we sought to represent processes of change and transition. As such, making visible movement and transformations became a key feature from utilising visual methods (Pink, 2012). Additionally, all data sets were compared for contradictions, nuances and what had been omitted (Brown et al., 2005).

The research we report is based on two relatively small-scale studies and of course has limitations. It was undertaken in the north of England and as such is situated within the array of agendas influenced by English government support programmes in the first decade of the 21st Century. It is therefore within this particular context of social enterprise that this article is empirically located. We have attempted to present various perspectives but as Bowey and Easton (2009) comment the absence of data or silent partners can mean that researchers may never fully understand what is occurring in its entirety. 


\section{Narratives of social enterprise}

This section presents interpretations of the emergent data, which we use to re-examine assumptions around the grand and counter narratives as discussed in the review of the literature. We utilise participants' stories, drawings and the notion of little narratives, to tease meaning out of the different understandings of being entrepreneurial and being in transition. From our analysis, these were emergent areas of negotiation and were not initial questions we set out to address.

\subsection{Differing views of being socially entrepreneurial}

Notions of social enterprise between those in social organisations and advisors differed from traditional views of being entrepreneurial; many stated relations were more complex as interactions were more than economic and included advice and support. An aspect of this was advisors' diagnostic questions when meeting with organisations. One said he played the role of the "cynic" and described this as asking "tough" questions focusing upon finances. These questions were similarly worded and the majority stated that their very first question was about money. As one advisor said:

"There is always a tension or a balance to be struck between social and enterprise activity. The first two questions I ask a social enterprise is [sic] 'Is there a market for it?' and 'How are they going to finance or fund it?'”

Advisors reflected upon finances and of changing ways of working to be more "businesslike". This approach is undoubtedly prompted by the need to meet their programme outputs (e.g. creating new social enterprises). But at the same time advisors commented that existing organisations were "vulnerable" due to changes occurring in how services were resourced and that a "transition phase" was not well acknowledged by local government and infrastructure agencies.

Participants repeatedly stated advisors and those organisational representatives selfidentifying as social enterprises had a "different language" from those in social 
organisations and were said to "talk the talk". This also highlights the nature of relationships and stories of cultural differences told. One advisor said:

\begin{abstract}
"The relationships are difficult and it is from the culture differences. I could caricature it as the difference between the well-meaning, badly organised, rather backward looking community sector that doesn't like the modernization agenda or the pace of change that is constantly accelerating. The voluntary community sector finds this very difficult ... Whereas the social enterprise sector is all gung-ho and tra-la-la-la and it loves modernization. It talks the talk and wears a suit most often, even the women. It is almost that obvious, the split between older, not so well dressed people looking backwards, and younger, better-dressed social enterprises looking forwards".
\end{abstract}

This would suggest the grand narratives and the counter-narratives are played out in every-day practice of views towards the modernity agenda, backwards and forwards looking, language and even the clothes they wear.

However, there was also a more nuanced view and various organisational representatives used the analogy of wearing different hats. Figure 2 illustrates the view of one who described that they wear different hats at different times to engage with different audiences. One hat was labelled "ours" towards the social end and at the other end, "market", is a hat that is worn to do business, in managing relations and operating outside the organisation.

Figure 2: Social enterprise as wearing different hats here

Others acknowledged that the culture within an organisation was being split as they took on members of staff to undertake the more traditional business-like functions such as monitoring and evaluation to be compliant with public sector funders' requirements. These comments appeared to associate entrepreneurial tensions as both inside and outside of the organisation. Moreover, data suggested identity work of both adopting social enterprise, as well as resisting it, within the same sentences and drawings. In the above instance (Figure 2), the organisational participants had dual identities implying contradictory practices. The hats image also suggests that their narratives will need to be positioned across various narratives in to order to interact with multiple and differing 
stakeholders. Notably, the participants appear to skilfully interpret and exploit ambiguity and contradiction to their benefit.

The analogy of hats was also used by an advisor saying organisations' representatives attending meetings in the role of advocates for the third sector needed to take off their individual "social enterprise hats" and not seek to win business/secure service delivery contracts in those situations. Thus implying a code of practice in professional conduct but there is more to the instruction. Many participants saw their advocacy roles as championing a cause; in doing so this role would run counter to the grand narratives of Government agendas - and counter to the work they did with their own "market" hats on which has repercussions around "biting the hand that feeds".

Some perceived enterprise as undermining the trust and the social nature of services. Nevertheless, they were nearly unanimous in suggesting their practices were becoming more "business-like" and in the current culture everyone needed to behave "entrepreneurially". As one explained:

"The entrepreneurship has to apply because, at the moment, we all are having to be entrepreneurs in order to survive. Which is different to organisations that are new and coming through from the start. And I think there is a difference between new organisations that are emerging, and start from scratch and established organisations that are changing, and doing things in a different way.

So, for me, for us, we're changing. And so we have this idea of enterprise because we need to be self-funding. But the other bit of that is we have to develop contract arrangements, service level agreements rather than the old grants. But we sort of worked out that's not going to be enough; we need to be sustainable without the contracts. Or, we'd like to be. Otherwise we are too dependent on the one particular area."

In the above excerpt the terms entrepreneurial and enterprise are used almost interchangeably. The participant discerned differences between new and existing organisations and stressed a pervasive context of change. For others, responding to a perceived need to diversify their organisational income, rather than perceived community 
need, was expressed as being entrepreneurial. Notably, none of the organisational participants specifically said that being entrepreneurial was about social change.

Respondents identified different meanings associated with social. For example, organisational representatives did not equate social with missions. These participants repeatedly spoke of the social as the "added value" of their service. This, for example, is how one described the hot meals service they provided into day care centres for the elderly:

\begin{abstract}
"We won this contract, sort of at the second attempt really - what it was, we lost it initially but the other firm that won it (another social enterprise) were too money driven - they'd streamlined the service into a very efficient model - so what they did was cut down the time spent in the centres - that way they got round more centres and were fast and slick at what they did - but to be honest there's more to this job than getting in and out fast - we make the effort to talk to people and that - I guess you could call it - added value - the nattering, the compassion - the other firm didn't do any of that - so to us we don't want to be driven that way."
\end{abstract}

The extract above underlines the nuanced perspectives towards cost-efficiency and nonrational aspects of doing business. Many had negative connotations to being "driven" to be more efficient, however. Participants' stories repeatedly were of this being an attribute of another firm, not theirs', which the above participant contrasts sharply with compassion and being aware that the social matters.

Nor were missions perceived to have drifted, as is the concern of the counter narrative, but rather changed to meet the needs of a wider "market". Numerous stories from those in social organisations were told. For instance, from specialising in specific markets or communities of interest (e.g. ethnic minority groups or lone parents) many recognized - in order to continue delivering services to these communities - the need to move to more general provision. Some acknowledged that this was initially resisted, but eventually accepted by others, such as staff, volunteers and board members in the organisations. For instance, a social enterprise widening service provision to gain public sector contracts for general elderly care in order to provide care to the Afro-Caribbean community, originally their social aim. Therefore, neither total acceptance nor radical rejection of the grand or counter narratives was seen. Instead a little narrative better describes these stories. 
Moreover, analysis of the data suggested that participants' understanding of the term market does not necessarily require them to become more like private sector organisations. From discussions it emerged the crux of such decisions was the reality of "trade offs", reconciling original views of social when economic decisions were made. Thus, it was not seen as win-win as presented in the grand narrative.

\subsection{Differing views of organisations in transition}

In examining the nature of transition, whilst Nyssens (2006) presents the idea as if organisations have already gone through this process, we found all in the state of change. Moreover, movement was a recurrent area of negotiation for both organisational representatives and advisors. Thus, the stories were not of a uni-directional aim, driving the narrative plot to become more like businesses.

Advisors enacted much of the grand narrative in practice

Advisors repeatedly stated they used the Department of Trade and Industry (DTI) definition of social enterprise as the basis of the support they offered, thus initially sounding to echo the grand narrative. Notably, one criterion differed from that of the DTI, and a comment repeatedly emphasised was that social enterprises needed to make a profit.

Utilising Dee's spectrum, advisors presented their role very positively in terms of helping to move organisations towards the economic aspect of social enterprise. As one stated "I hope people see l've got the oilcan and am hoping to go around making it easier for them". Only, one advisor stated organisations "might feel they were being pushed" into social enterprise.

Table 1 here 
The language used by advisors implied that they are enacting a story of the process of changing social organisations to the shape they understand best resembles social enterprise. The metaphor offered an insight that they assumed a cause-and-effect relationship might be achieved by social organisations taking on business practices from the private sector, becoming more efficient, more competitive, business-like and successful.

\section{Organisational representatives enacted more nuanced views}

Organisational representatives' views of transition differed from those articulated by advisors. Rather than a smooth linear transition of organisations from social to economic, in line with the grand narrative and the analogy of the rising tide of commercialisation of non-profits, a more nuanced view of social enterprise emerged. Organisational representatives annotated the original spectrum to indicate their perceptions that their organisations were changing. Figure 3 is a composite drawing recreated from 13 of the 36 organisational participant's individual drawings. The pattern of movement in their individual drawings is what is of interest.

Figure 3 Arrows depicting movement here

The explanations are nearly unanimous in suggesting their practices were becoming more "business-like" (if only slightly in some instances). Initially, this suggests they fall within the grand narrative. There were various reasons for this, including: more of a focus on trading; the need to appeal to the financiers (funders or contractors); to accommodate the trend towards branding social enterprises; or simply as a strategy that would (eventually) support the pursuit of social objectives. Two indicated movement towards the social end of the spectrum. These participants explained that they had "given up too much"; one said they had become too "business-like" and the organisation he represented needed to revert back to the origins of the organisation. This reinforces the imagery of struggle within the everyday practices and talk of social enterprise. But it does not capture the counter-narrative as there appears no radical resistance, but rather two lone arrows going against the stream. Yet, the expectation that these organisations will traverse the spectrum to the enterprise end is curious. According to Dees (2009), 
commercial strategies are not 'optimal' for all social enterprises, and Alter (2004, p.7) notes that 'organizations rarely evolve or transform in type along the full spectrum'.

\subsection{Stories and drawings depicting little narratives}

Whilst some organisational representatives were able to engage and place a mark or arrow upon the spectrum, others were unable able to do so saying it was too "simplistic" to place a simple mark to denote their location. The following drawings and stories offer examples suggesting other views, which we present to offer empirical evidence to support little narratives.

One organisational representative gestured with some anger at the continuum, as can be seen in Figure 4, the pencil mark dots that were caused by the machine gun-like action to vehemently refuse the analogy of harmonious balancing of goals and/or linear movement towards enterprise as a goal in itself. He drew a line that bent back towards the social pole, which he circled to emphasis his point. This participant stated that the only reason they were moving towards the enterprise end of the spectrum was in order to achieve the social, and not to become more business-like per se.

Figure 4: View that movement towards enterprise was to achieve the social Figure 4 here

Another organisational representative said that the "culture mostly" was near the social end, but the way they earned money was near the economic end of the spectrum. Like others, he said there was no hybrid but two (or more) identities and ways of working within one organisation. This story reinforces the imagery of wearing different hats.

Another organisational representative described:

"When times are good we'd be more mission-driven. When times are bad we'd be more market driven. So, at the moment, we're middle stroke market driven, but when profits are good and we can be philosophical and philanthropic, then we are more mission-driven. And philanthropy is a really interesting area around what we do and what anybody does really." 
Some of the above drawings seem to support the rising tide in the grand narrative towards the commercialisation end of the spectrum. However, the reasoning runs counter to Dees' and other academic theorising. This point is drawn out in Figure 5, the above participant's drawing illustrating this pattern of flux.

\section{Figure 5 here}

Figure 5: Counter-intuitive perception of good and bad times

Social enterprise economic activity was not perceived as a positive step; in "bad times" they concentrated upon economic goals and pull back from the social aspects of networking activities and the promotion of their mission. This insight underlies the complex ways which talk of identity informs everyday meanings and actions.

In this account of our empirical studies we have explored views in the context of plural ways of making sense of the social and economic in social enterprise and public services. From stories and drawings we found instances of the grand narrative and discussion of the differences in culture and language seemingly supporting the counter-narrative with a caricature between the grand and counter narratives being played out in practice. However, it was participants' drawings that helped to illustrate and draw out the more nuanced little narratives of iterative processes of transformation and the importance of motion in their stories of change.

\section{Implications for theory and practice}

In navigating through the competing claims and counter claims of the influence of narratives, the discussion relates findings to different strands in research that informs the fields of social enterprise and social entrepreneurship and suggests implications for the direction of future research. The little narrative raises implications of unconventional ways of understanding entrepreneurship (Berglund, 2006). Our research has highlighted the interpretive practices of representatives of social organisations and advisors in social enterprise support agencies, which departs from conceptualisations of social enterprise within either the grand and/or counter narratives. We acknowledge this presents a challenge to the direction of future research and call for the conflicting and critical views of practitioners to come to the fore. 
Utilising little narratives, our research identifies three inter-woven narrative strands within our themes of organisations in transition and being entrepreneurial: (i) identity; (ii) the linear model; and (iii) the positive aspects of paradox. Stories and drawings provided rich imagery for considering how practitioners (as well as we as researchers) make sense of social enterprise. Practitioners had different views about where they perceived their current situations of social enterprise and the paths of their organisations for surviving. Whilst we began with no preconceptions of the conversations that unfolded, reflected by asking research participants if they could position their organisations upon the linear social enterprise spectrum, the overwhelmingly enthusiasm of participants to pick up the pencil was exciting to us as researchers.

Those in our study said they needed to be entrepreneurs. This is not to say they were not struggling with this identity or way of acting. In this way, data reflected Ellis and Ybema's (2010) findings of shifting entrepreneurial identity. The diverse interpretations of being entrepreneurial expressed by participants differs from Parkinson and Howorth's (2008) and Howorth's et al. (2011) findings that business language and actions are not meaningful at all. Their research identified relationships between mission, philosophy and the macro narrative. In addition to their insights, which we pose as the counter narrative, we add an analysis of the iterative processes in day-to-day concerns of doing business and maintaining multiple identities and ways of working (the little narrative).

Far ranging and contradictory views of social enterprise were held, which offered an insight to diversity and complexity. These were between organisational representatives and advisors; within the group of participants representing different organisations; and also expressed by participants indicating contradictory notions within their individual stories. Narratives included enthusiasm and acceptance (the grand narrative); that enterprise was the dark side to be avoided where possible, or raided on a smash and grab basis (the counter narrative); to more nuanced views of practice (the little narratives). While it was commonly agreed that everyone must be "entrepreneurial" in these times to survive, our research highlighted significant variation in how practitioners interpret what being entrepreneurial means. Furthermore, our findings do not correspond with research that suggests social enterprises are similar to other types of enterprise (Steinerowski et al., 2008; Kreuger et al., 2009). 
Identity appeared to offer views of culture, but also uncovered multiple-identities. Unlike Berglund and Wigren (2012), our findings suggest that organisational representatives can at times dress in the 'clothes of the entrepreneur' and put on and take off their 'entrepreneur' hats for going to market. Like Grenier (2006), we acknowledge that perceived identity is crucial, especially of advisors enacting government policy, as they were influential in accessing resources, shifting the organisational identities (or at least the performance of perceived legitimised entrepreneurial identity) and ways of working within our research. This is not to imply symmetrical power relations. Of course, freedom is always contingent upon unequal power relationships between social organisations and public service advisors and commissioners. But unlike Grimes et al. (2010), we found organisational representatives did not passively accept a singular social enterprise identity but took advantage of ambiguous identities in their dealings with others, including funders, as well as making sense of their actions within the organisation. Hence, we refrain from referring to them all as social entrepreneurs.

Movement and motion were crucial aspects for uncovering the progression of events in the development of the various narrative plots, something which we feel merits further research. The overall pattern was not of linear transition but of incremental movements, which at times appeared counter-intuitive from the grand narrative. Nevertheless, neither did we uncover substantial evidence of radical pattern breaking behaviour. This finding reflects that of Steyaert and Hjorth (2006), further emphasising the need to understand movement in the study of entrepreneurship and to be mindful that, as researchers, we are 'producing' where theorizing is taking us. It does not appear that practitioners view social enterprise as a harmonious hybrid between the social and economic; nor, though, did their responses suggest that language and ideas from the business world were undermining social priorities.

The stories (and images) are of social organisations: (i) oscillating between the social and economic; (ii) evolving from, whilst retaining aspects of, the traditions of the third sector;(iii) anticipating direction towards social goals (seen as being more than organisational missions, and including social values, notions of added-value, views of networking practices and change). As such, their stories differ from both the grand and counter narratives. In this way we differ from Alter (2004) and find the social is more than mission related. In reconsidering the underlying issue of a rising tide of commercialisation, we have revisited Dart's (2004) analysis that the social was being pushed aside in social 
enterprise. Whilst this transition might capture the macro-narrative of political agendas taking place at the level of international and national governments, as well as the influence of policies that have funded the sector support agencies and their engagement with the sector through business narratives, it does not reflect the micro-narrative of stories amongst all practitioners in our studies. Whilst this in part corresponds with Parkinson and Howorth's (2008) and Howorth et al.'s (2011) findings, the different types of movement identified by participants illustrates how some organisations have negotiated these two stories. One might call this approach a tactical performance in wearing different hats, in other words managing the impression of being enterprising; where the everyday culture, though being split, was still more social. We suggest within this group the meaning of being entrepreneurial also differs from traditional notions.

Our findings suggest transition occurring for existing organisations often over long periods of time, yet, participants repeatedly said that "everything changes yet stays the same". This final insight is by no means the least significant. Indeed, a core theoretical issue underlying the discussions is paradox as a positive feature inherent in social enterprise. This approach is rarely found in extant research although some writers recognise it (e.g. Curtis, 2008; Scott, 2010) and it is entirely consistent with the notion of 'little narratives' (Dey and Steyaert, 2010). Conceiving of paradox as a positive aspect of social enterprise by questioning unspoken assumptions might enable the field to move beyond the construct of a linear model in which metaphors of balance are sought by framing social as the polar opposite to economic.

\section{Concluding thoughts}

In offering critical analysis of the narratives of theory and everyday practice, we think it fundamental to call to attention the contradictions and paradoxes of the term social enterprise. We have sought to investigate aspects of transition to social enterprise through interpretivist interviews with organisational representatives and sector support advisors in the context of government policies that enrol them to become public service providers in a fragmented market environment. The implications from our research point to more than oxymoron in the amalgamation of the term social enterprise (Arthur et al., 2009) but the paradoxical nature in the narratives used in practice. 
Using movement, we attempt to open up the narrative to better understand social enterprise practices (and emotions) in the transition of shifting identities, actions and narratives, which are occurring over time. There appear contrasting narratives and differing paths in transition, not simply a linear journey to commercialisation. Moreover, you can't get there from here offers an adage that echoes the situation of many social organisations. Exactly where the destination is remains unclear, but what we have opened up in this paper is space for the discussion of where participants see their organisations, that may offer a new starting point to build upon and examine the routes and destinations.

Much of the context of social enterprise in the UK, especially in England, lies within the delivery of public services, together with recent emphasis of the Coalition government upon austerity through cuts to public sector funding. Faced with uncertainty and a threat to traditional ways, entrepreneurship comes to the fore. This area of research therefore is timely for exploring further within the nations of the UK, and also in other national contexts in the light of growing importance attached to social organisations in public services as an international phenomenon (Lyon and Glucksmann, 2008; Pestoff and Brandsen, 2010).

Our research provides evidence to support 'narrations of the social' (Dey and Steyaert, 2010). We identify that despite the enactment of the grand narrative in the advice and support from advisors to those in transition, the organisational representatives in our study acted differently to conventional entrepreneurship. But, they also spoke and acted differently from what is presented as the counter narrative. We have also illustrated the potential for applying a repertoire of participant generated visual data. Evidence from these processes emphasises that social enterprise cannot be told as a single story but as a set of little narratives showing ambiguities, contradictions and paradox. This has been a particularly important aspect of the research.

We see the findings of our research relevant for policy and practice, as the nature of transition is key to envisaging and devising contextually appropriate support infrastructure. To assume there is but one way to develop social enterprise is to limit what 
is possible by recognising ambiguity and paradox (as posited by Steyaert and Hjorth, 2006). This research will, we hope, provoke debate and argument about how socially entrepreneurial activities are perceived, negotiated and managed in the turbulent environment of public service delivery. In particular, it demonstrates how some types of business-like identity and practice are enacted and others are challenged by social organisations in transition, where the adage you can't get there from here resonates with not only their starting point and current situation but also the imagined future journey of identity and ways of working. As we learnt from practice, there and here are more complex places than the literature suggests.

\section{References}

Alcock, P. (2010), "Building the Big Society: a new policy environment for the third sector in England", Voluntary Sector Review, Vol. 1 No.3, pp. 379-389.

Alter, K. (2004), Social Enterprise Typology, Available at http://www.virtueventures.com/resources/setypology (accessed August, 2011).

Arthur, L., Scott Cato, M., Smith, R. and Keenan, T. (2009), Where is the 'social' in social enterprise. In Fuller, D., Jonas, A.E.F. and Lee, R. (eds.) Interrogating alterity: Alternative economic and political spaces, Ashgate, Aldershot, pp. 207-222.

Bacq, S. and Janssen, F. (2011), "The multiple faces of social entrepreneurship: A review of definitional issues based on geographical and thematic criteria" Entrepreneurship and Regional Development, Vol. 23, No.5-6, pp. 373-403.

Baines, S., Bull, M. and Woolrych, R. (2010), “A more entrepreneurial mindset? Engaging Third Sector suppliers to the NHS", Social Enterprise Journal, Vol. 6 No. 1, pp.49-58.

Berglund, K. (2006) Discursive diversity in fashioning entrepreneurial identity. In Steyaert, C. and Hjorth, D. (eds.), Entrepreneurship as Social Change, Cheltenham, Edward Elgar pp. 231-250.

Berglund, K and Wigren, C (2012) "Soci(et)al Entrepreneurship: The shaping of a different story of entrepreneurship", Journal of Critical Organization Inquiry, Vol. 10 No. 1, pp. 922.

Birch, K. and Whittam, G. (2008), "The Third Sector and the regional development of social capital”, Regional Studies, Vol. 42 No. 3, pp. 437-50.

Blackburn R. and Kovalain, A. (2009), "Researching small firms and entrepreneurship: Past, present and future", International Journal of Management Reviews, Vol. 11 No. 2, pp. $127-148$. 
Boschee, J. (2006), Social Entrepreneurship: The Promise and the Perils. In Nicholls, A. (ed.) Social Entrepreneurship: New Paradigms of Sustainable Social Change, Oxford University Press, Oxford, pp. 356-390.

Bowey, J. L. and Easton, G. (2007), “Entrepreneurial social capital unplugged: an activitybased analysis", International Small Business Journal, Vol. 25 No. 3, pp. 273-306.

Brown, A.D., Stacey, P. and Nandhakumar, J. (2008), "Making sense of sensemaking narratives”, Human Relations, Vol. 61 No. 8, pp.1035-1062.

Buckingham, H. (2009), “Competition and contracts in the voluntary sector: exploring the implications for homelessness service providers in Southampton", Policy and Politics, Vol. 37 No. 2, pp.235-254.

Bull, M. (2008) "Challenging tensions: critical, theoretical and empirical perspectives on social enterprise", International Journal of Entrepreneurial Behaviour \& Research, Vol. 14 No. 5 , pp.268-275.

Casson, M. (2005), The entrepreneur: An economic theory. Oxford, Oxford University Press.

Czarniawska, B., (1998), A Narrative Approach to Organization Studies, Sage, Thousand Oaks, CA.

Chell, E. (2007), "Social enterprise and entrepreneurship: towards a convergent theory of theentrepreneurial”, International Small Business Journal, Vol. 25 No. 1, pp.5-26.

Chell, E., Nicolopouloua, K. and Karatas-Ozkan, M. (2010), "Social entrepreneurship and enterprise: International and innovation perspectives", Entrepreneurship and Regional Development, Vol. 22, No. 6, pp.485-493.

Cope, J. (2005), "Researching entrepreneurship through phenomenological inquiry: philosophical and methodological issues", International Small Business Journal, Vol. 23 No. 2, pp.163-190.

Curtis, T. (2008), "Finding that grit makes a pearl: a critical re-reading of research into social enterprise", International Journal of Entrepreneurial Behaviour and Research, Vol.14 No. 5, pp.276-290.

Dart, R. (2004), “The Legitimacy of Social Enterprise", Nonprofit Management and Leadership, Vol.14 No.4, pp.411-424.

Darwin, J., Johnson, P. and McAuley, J. (2002), Developing strategies for change, Prentice Hall, Harlow, England.

Dees, J. G. (1998), “Enterprise Non-profits”, Harvard Business Review, Vol. 76 No.1, pp. 55-67.

Dees J. G. and Anderson B. B. (2006), Framing a Theory of Social Entrepreneurship: Building on Two Schools of Practice and Thought. In Mosher-Williams, R. (ed.), Research on Social Entrepreneurship: Understanding and Contributing to an Emerging Field, ARNOVA, Indianapolis, pp.39-66. 
Defourny, J. and Nyssens, M. (2006), Defining Social Enterprise. In Nyssens, M. (ed.), Social Enterprise - At the Crossroads of Market, Public Policies and Civil Society, Routledge, London, pp.3-26.

Dey, P. (2006), The rhetoric of social entrepreneurship: parology and new language games in academic discourse. In Steyaert, C. and Hjorth, D. (eds.) Entrepreneurship as Social Change,Edward Elgar, Cheltenham, pp.121-141.

Dey, P. and Steyaert, C. (forthcoming), Critical reflections on social entrepreneurship. In Volkmann C.K., Tokarski K.O. and Ernst, K. (eds.) Social Entrepreneurship and Social Business: An introduction and discussion with case studies, Gabler Verlas, Wiesbaden.

Dey, P. and Steyaert, C. (2010), “The politics of narrating social entrepreneurship”Journal of Enterprising Communities, People and Places in the Global Economy, Vol. 4 No 1, pp. 85-108.

Down, S. (2006), Narratives of Enterprise Crafting entrepreneurial self-identity in a small firm, Edward Elgar, Cheltenham.

Down, S. and Warren, L. (2008), "Constructing narratives of enterprise: clichés and entrepreneurial self-identity", International Journal of Entrepreneurial Behaviour and Research,Vol.14 No.1, pp.4-23.

Down, S. (2010) Enterprise, Entrepreneurship and Small Business. London: Sage

DTI (2002) A strategy for success. London: Department of Trade and Industry [online] Available at: <http://www.dti.gov.uk/nrustrategy/index.html> (accessed October 2007).

du Gay, P. (2004) 'Against 'Enterprise' (but not against 'enterprise', because that would make no sense)', Organization, 11, pp.37-58.

Dunford, R. and Jones, D. (2000) "Narrative in strategic change", Human Relations, Vol. 53 No.9, pp.1207-1226.

Eikenberry, A. M. and Kluver, J. D. (2004), "The marketization of the nonprofit sector: civil society at risk?”, Public Administration Review, Vol. 64 No. 2, pp.132-140

Eisenhardt, K. M. and Graebner, M. E. (2007), “Theory building from cases: Opportunities and challenges", Academy of Management Journal, Vol. 50 No. 1, pp.25-32.

Ellis, N. and Ybema, S. (2010), “Marketing Identities: Shifting Circles of Identification in Inter-organizational Relationships”, Organization Studies, Vol. 31 No. 3, pp.279-305.

Emmel, N. (2008), Participatory mapping: an innovative sociological method. Real life methods ESRC funded project Toolkit 03 available at: http://eprints.ncrm.ac.uk/540/ (accessed June 2011).

Foster, W. and Bradach, J. (2005), "Should Non-Profits Seek Profits?", Harvard Business Review, Vol. 83 No. 2, pp.92-100. 
Froggett, L. and Chamberlayne, P. (2004) "Narratives of social enterprise: from biography to practice and policy critique", Qualitative Social Work, Vol. 3 No. 1, pp.61-77.

Gartner, W. B. (2007), "Entrepreneurial narrative and a science of the imagination", Journal of Business Venturing, Vol. 22, pp.613-627.

Goldstein, J., Hazy, J. and Sibberstang, J. (2008) "Complexity and social entrepreneurship: a fortuitous meeting", Emergence: Complexity and Organization, Vol. 10 No. 4, pp. 9-24. [online] Available at: <http://find.articles.com/p/articles/mi_7525/is_200807/ai_n32302989/> (accessed November 2009).

Grenier, P (2002), “The function of social entrepreneurship in the UK” [online] Available at: <http://www.istr.org/conferences/capetown/volume/grenier.pdf> (accessed August 2011).

Grenier, P. (2006), Social entrepreneurship: agency in a globalizing world. In Nicholls, A. (ed.) Social Entrepreneurship: New Paradigms of Sustainable Social Change, Oxford University Press, Oxford, pp.119-143.

Grimes, M. (2010), "Organizational identity in the social sector", Entrepreneurship Theory and Practice, Vol. 34 No. 4, pp.763-783.

Guillemin, M. (2004), “Understanding Illness: Using drawings as a research method”, Qualitative Health Research, Vol. 14 No. 2, pp.272-289.

Haugh, H. and Kitson, M. (2007), "The Third Way and the third sector: New Labour's economic policy and the social economy", Cambridge Journal of Economics, Vol. 31 No. 6, pp.973-994.

Hjorth, D. (2007), “Lessons from lago: Narrating the event in entrepreneurship", Journal of Business Venturing, Vol. 22 No. 5, pp.712-732.

HM Treasury (2002) The role of the voluntary and community sector in service delivery: $a$ cross cutting review London: Her Majesty's Treasury.

Hogg E.and Baines S. (2011), "Changing Responsibilities and Roles of the Voluntary and Community Sector in the Welfare Mix: A Review", Social Policy and Society, Vol. 10 No.3, pp.341-352.

Howorth, C., Parkinson, C. and MacDonald, M. (2011), Discursive chasms: an examination of the language and promotion of social enterprise. In Southern, A. (ed.) Enterprise and Deprivation: Small Business, Social Exclusion and Sustainable Communities, Routledge, London, pp.222-238.

Jones, C. and Spicer, A. (2009), Unmasking the Entrepreneur Edward Elgar, Cheltenham.

Jones, R., Latham, J. and Betta, M. (2008), "Narrative construction of the social entrepreneur identity", International Journal of Entrepreneurial Behaviour and Research,Vol. 14 No. 5, pp.330-345. 
Krueger, N., Kickul, J., Gundry, L., Verman, R. and Wilson, F. (2009) Discrete choices, trade-offs and advantages: modelling social venture opportunities and intentions. In Robinson et al. (eds.) International perspectives on social entrepreneurship, Basingstoke, Hampshire, UK, Palgrave Macmillan, pp.117-144.

Liamputtong, P. and Ezzy, D. (2005), Qualitative Research Methods, $2^{\text {nd }}$ edition, Oxford University Press, Oxford.

Lyon, D. and Glucksmann, M. (2008), “Comparative configurations of care work across Europe", Sociology, Vol. 42 No. 1, pp.101-18.

Mason, C., Kirkbride, J. and Bryde, D. (2007), "From stakeholders to institutions: the changing face of social enterprise governance theory", Management Decision, Vol. 45 No.2, pp.284-301.

Meyer, A. D. (1991), "Visual Data in Organisation Research", Organization Science, Vol.2 No. 2, pp.218-236.

Milbourne, L. (2009), "Remodelling the Third Sector: Advancing Collaboration or Competition in Community-based Initiatives?", Journal of Social Policy, Vol. 38 No.2, pp. $1-21$.

Milligan, C. and Fyfe, N. R. (2004), "Putting the Voluntary Sector in its Place: Geographical Perspectives on Voluntary Activity and Social Welfare in Glasgow", Journal of Social Policy, Vol. 33 No. 1, pp.73-93.

Mitchell, C. (2011), Doing Visual Research. Sage Publications, London.

Nicholls, A. (2006), Social Entrepreneurship: New Paradigms of Sustainable Social Change. Oxford University Press, Oxford.

Nicholls, A. (2010) "The Legitimacy of Social Entrepreneurship: Reflexive Isomorphism in a Pre-Paradigmatic Field”, Entrepreneurship Theory and Practice, Vol. 34 No. 4, pp.611633.

Nyssens, M. (2006) Social Enterprise at the Crossroads of Market, Public and Civil Society. London: Routledge.

OTS (2007) Social Enterprise Action Plan: Scaling New Heights. London: Office of the Third Sector.

Parkinson, C. and Howorth, C. (2008), "The language of social entrepreneurs", Entrepreneurship and Regional Development, Vol. 20 No. 3, pp.285-309.

Peattie, K. and Morley, A. (2008), A research monograph social enterprises: diversity and dynamics, contexts and contributions, Cardiff University: ESRC Centre for Business Relationships, Accountability and Society (BRASS).

Perrini, F. (2006), The new social entrepreneurship: what awaits social entrepreneurial ventures? Edward Elgar, Cheltenham. 
Pestoff, V. and Brandsen, T. (2010), Public governance and the Third Sector: Opportunities for co-production and innovation. In Osborne. S. (ed.) The New Public Governance? Emerging Perspectives on the Theory and Practice of Public Governance, Routledge, London, pp. 223 - 236.

Pink, S. (2012) Situating everyday life: Practices and places. Sage, London.

Prosser, J and Loxley, A (2008), Introducing Visual Methods, National Centre for Research Methods, http://eprints.ncrm.ac.uk/420/(accessed June 2011).

Reid, K and Griffith, J (2006) "Social enterprise mythology: critiquing some assumptions", Social Enterprise Journal, Vol. 2, No. 1, pp.1-10.

Ridley-Duff, R. and Bull, M, (2011), Understanding social enterprise - theory and practice, Sage, London.

Riessman, C. K. (1993), Narrative Analysis. Qualitative Research Methods Series, No. 30. Sage, Newbury Park, CA.

Rodgers, C. (2007), Informal coalitions: mastering the hidden dynamics of organizational change. Palgrave, Basingstoke, England.

Rose, G. (2008), Visual Methodologies: An Introduction to the Interpretation of Visual Materials, Sage Publications, London.

Scott, D. (2010), Black boxes in the wreckage? Making sense of failure in a third sector social enterprise, Third Sector Research Centre Working Paper 31 http:// www.tsrc.ac.uk/LinkClick.aspx?fileticket=kST4jhqoOH0\%3Dandtabid=500(Accessed August 2011).

Shane, S. and Venkataraman, S. (2000)'The promise of entrepreneurship as a field of research'The Academy of Management Review, Vol. 25 No.1, pp. 217 - 226

Steinerowski, A., Jack, S. and Farmer, J. (2008) 'Who are social entrepreneurs and what do they actually do' [online] Available at: <http://www.babson.edu/entrep/fer/2008FER/chapter_21/paper_xxi_2.html> (accessed December 2009).

Steyaert, C. (2007), "Entrepreneuring as a conceptual attractor? A review of process theories in 20 years of entrepreneurship studies", Entrepreneurship and Regional Development Vol. 19 (Winter), pp.453-477.

Steyaert, C. and Hjorth, D. (2005), Narrative and discourse approaches in entrepreneurship: A second movements in entrepreneurship. Edward Elgar, Cheltenham.

Steyaert, C. and Hjorth, D. (2006), Entrepreneurship as social change: A third movements in entrepreneurship book, Edward Elgar, Cheltenham.

Stiles, D. R. (2004), Pictorial Representation. In Cassell C. and Symon, G. (eds.), Essential Guide to Qualitative Methods in Organizational Research Sage, London, pp. 127-139. 
Teasdale, S. (2011), "What's in a name? The construction of social enterprise, making sense of social enterprise discourses", Public Policy and Administration, Vol. 27 No.2, pp. 99-199.

Tracey, P., Phillips, N. and Haugh, H. (2005), “Beyond Philanthropy: Community Enterprise as a Basis for Corporate Citizenship", Journal of Business Ethics, Vol. 58 No. 4, pp.327344.

Warren, S. (2009), "Visual methods in organizational research", in Handbook of Organizational Research methods, Bryman, A. and Buchanan, D. (eds.), Sage Publications, London, pp.566-582.

Weick, K. (1995), Sensemaking in Organizations, Sage, Thousand Oaks, CA.

Westall, A. and Chalkley, D. (2007), Social Enterprise Futures, London: The Smith Institute. Available at http://www.smith-institute.org.uk/file/SocialEnterpriseFutures.pdf (accessed August 2011). 